Nuclear Waste Treatment Program

\title{
Statistical Process Control Applied to the Liquid-Fed Ceramic Melter Process
}

B. A. Pulsipher

W. L. Kuhn

September 1987

Prepared for the U.S. Department of Energy under Contract DE-AC06-76RLO 1830

Pacific Northwest Laboratory Operated for the U.S. Department of Energy by Battelle Memorial Institute 


\section{DISCLAIMER}

This report was prepared as an account of work sponsored by an agency of the United States Government. Neither the United States Government nor any agency thereof, nor Battelle Memorial Institute, nor any of their employees, makes any warranty, expressed or implied, or assumes any legal liability or responsibility for the accuracy, completeness, or usefulness of any information, apparatus, product, or process disclosed, or represents that its use would not infringe privately owned rights. Reference herein to any specific commercial product, process, or service by trade name, trademark, manufacturer, or otherwise, does not necessarily constitute or imply its endorsement, recommendation, or favoring by the United States Government of any agency thereof, or Battelle Memorial Institute. The views and opinions of authors expressed herein do not necessarly state or reflect those of the United States Government or any agency thereof, or Battelle Memorial Institute.

\section{PACIFIC NORTHWEST LABORATORY operated by \\ BATTELLE MEMORIAL INSTITUTE for the \\ UNITED STATES DEPARTMENT OF ENERGY under Contract DE-AC06-76RLO 1830}

\begin{tabular}{|c|c|}
\hline \multirow{2}{*}{\multicolumn{2}{|c|}{ Printed in the United States of America }} \\
\hline & \\
\hline \multicolumn{2}{|c|}{ Available from } \\
\hline \multicolumn{2}{|c|}{$\begin{array}{l}\text { National Technical Information Service } \\
\text { United States Department of Commerce }\end{array}$} \\
\hline \multicolumn{2}{|c|}{5285 Port Royal Road } \\
\hline \multicolumn{2}{|c|}{ Springfield, Virginia 22161} \\
\hline \multirow{2}{*}{\multicolumn{2}{|c|}{$\begin{array}{l}\text { NTIS Price Codes } \\
\text { Microfiche A01 }\end{array}$}} \\
\hline & \\
\hline \multicolumn{2}{|c|}{ Printed Copy } \\
\hline & Price \\
\hline Pages & Codes \\
\hline 001-025 & A02 \\
\hline $026-050$ & $\mathrm{~A} 03$ \\
\hline $051-075$ & A04 \\
\hline $076-100$ & A05 \\
\hline $101-125$ & A06 \\
\hline $126-150$ & A07 \\
\hline 151-175 & $\mathrm{A} 0 \mathrm{~B}$ \\
\hline $176-200$ & A09 \\
\hline $201-225$ & A010 \\
\hline $226-250$ & A011 \\
\hline $251-275$ & A012 \\
\hline $276-300$ & A013 \\
\hline
\end{tabular}


NUCLEAR WASTE TREATMENT PROGRAM

STATISTICAL PROCESS CONTROL

APPLIED TO THE LIQUID-FED

CERAMIC MELTER PROCESS

B. A. Pulsipher

W. L. Kuhn

September 1987

Prepared for

the U.S. Department of Energy

under Contract DE-AC06-76RLO 1830

Pacific Northwest Laboratory

Richland, Washington 99352 
. 


\section{$\underline{\text { SUMMARY }}$}

The United States Department of Energy (DOE) is managing several programs to dispose of existing liquid high-level nuclear waste by vitrification in borosilicate glass in a ceramic-lined melter and casting the glass in canisters for shipment to a federal geologic repository. It is desirable to establish relationships between control of the vitrification process and quality of the glass product in order to establish acceptance of vitrified high-level nuclear waste at a licensed Federal repository. Because compliance with product specifications is expected to be primarily through demonstration of a certain product composition, an established quality control program would substantiate claims to a quality product.

Modeling activities are underway to relate product composition, determined from feed samples, to glass product quality. The reliability of the measures of product quality derived from these models will be directly affected by the reliability of the determinations of feed sample composition. Thus, to control product quality, one must control the many factors affecting feed composition. A widely applied standard method for quality control is statistical process control (SPC). The purposes of SPC are to identify when the process changes beyond its expected, inherent variations, and to aid in improving the process. The many tools of this method could be applied to various aspects of the waste glass production process. The basic premise behind SPC is that all processes vary. The question addressed by SPC concerns the degree to which a process is allowed to vary before it is determined to be changed or out of control. If the process is not in statistical control, the reliability of product quality predictions based on apparent feed compositions will not be known.

In this report an application of one SPC tool (control charts) to the apparent feed composition of a Liquid-Fed Ceramic Melter (LFCM) is demonstrated by using results from a simulation of the LFCM system. Usual applications of control charts require the assumption of uncorrelated observations over time. This assumption is violated in the LFCM system because of the heels left in tanks from previous batches. Methods for dealing with this problem have been developed to create control charts for individual batches sent to the feed 
preparation tank (FPT). These control charts are capable of detecting changes in the process average as well as changes in the process variation.

Because the initial setup of control charts requires estimates of a number of variance components and because most vitrification projects are limited by the number of batches of waste processed, simulated data may prove helpful in setting up control charts. As actual process data become available, controi charts should be updated to reflect actual variabilities.

SPC techniques provide valuable assistance in determining appropriate sampling schemes for the LFCM process by examining the capability to control product quality using SPC tools. By examining the average run length for detecting shifts with a control chart, questions such as the following could be answered: Where should sampling be implemented?, How many samples should be taken?, How many analyses per sample should be performed?, What is the effect of taking more samples at one point in the process and less at another point? Data obtained from simulated FPT batches showed that a process upset of $10 \%$ from the mean feed composition could not be detected until after at least 20 batches of feed had been processed. However, a 25\% shift in the process was detectable anywhere from one to eight batches after the shift, depending on the sampling scheme. If it is desirable to detect smaller shifts with fewer batches, either additional samples and analyses are needed or the sources of variation must be isolated and reduced. If SPC were applied throughout the process, it would be a helpful tool for decreasing the total variability.

Reducing variations in the feed composition, thereby improving product quality, could be accomplished by making the true feed composition closer to the target composition. A plausible scenario for decreasing the difference between the true feed composition and the target composition is to hold material in the feed preparation tank for adjustment based on the results of the compositional analysis of the feed samples. A decision rule based on SPC techniques is developed which determines whether adjustment to the feed composition is needed. It is shown that if adjustment is automatically carried out without considering the inherent sampling and analytical variations, there is a chance of increasing rather than decreasing the differences between the true feed composition and the target composition. 
It should be remembered that all numbers reported in this document were derived from a simulated demonstration of a plausible LFCM system. In practice, site-specific data must be used as input to a simulation tailored to that site. These data directly affect all variance estimates used to develop control charts. 


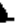




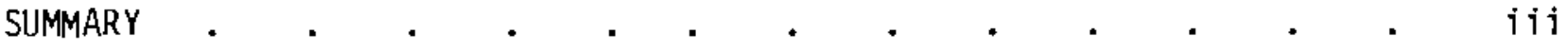

1.0 INTROOUCTION

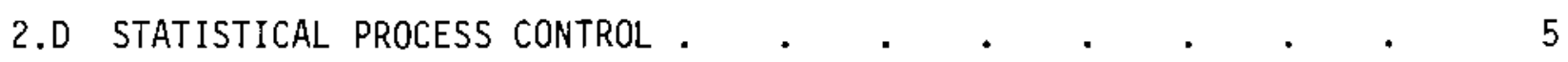

2.1 APPLICATIONS IN U.S. INDUSTRY $\quad . \quad$. $\quad . \quad . \quad$. $\quad . \quad 5$

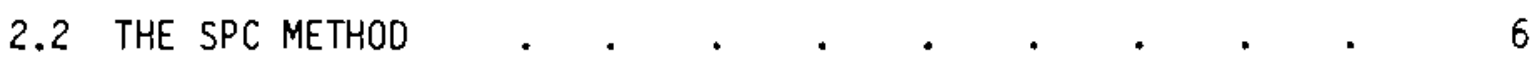

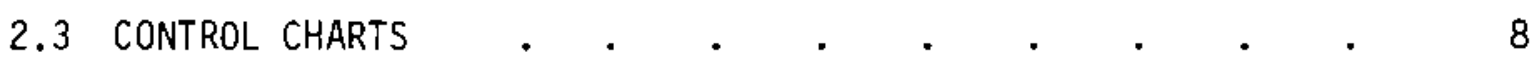

3.0 IMPLEMENTING SPC ON THE LIQUID-FEO CERAMIC MELTER (LFCM) . • $\quad 11$

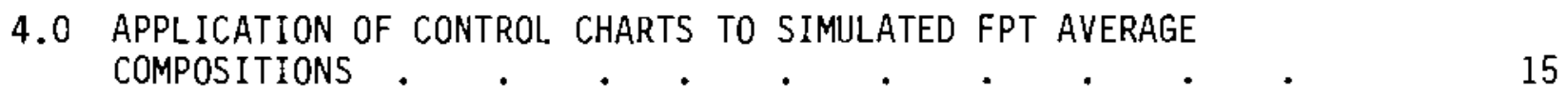

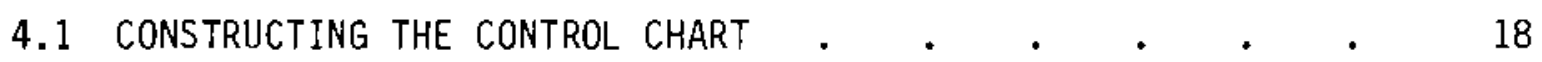

4.2 UPOATING CONTROL LIMITS FROM ACTUAL PROCESS DATA $\quad$ - $\quad 19$

5.0 QUALITY CONTROL CAPABILITY AND SAMPLE SIZE STUDIES $\quad . \quad$ • $\quad$ • 21

6.0 SPC AS A GUIDE FOR FURTHER FEED ADJUSTMENTS . . • • . . . 25

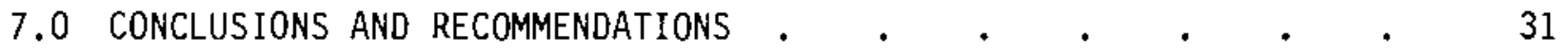

8.0 REFERENCES . . . . . . . . . . . . . . . . . . 33

9.0 ADDITIONAL CASE STUDY ARTICLES AND COLLECTIONS RELATED TO SPC . 35

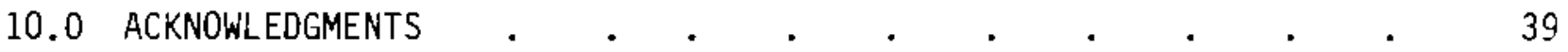



STATISTICAL PROCESS CONTROL APPLIED TO

THE LIQUID-FED CERAMIC MELTER PROCESS

\subsection{INTROOUCTION}

The United States Department of Energy (DOE) is managing several programs to dispose of existing liquid high-level nuclear wastes in the United States by vitrification in borosilicate glass in a ceramic-lined melter and casting the glass in canisters for shipment to a federal geologic repository. During FY 1982, the DOE assigned responsibility for managing civilian nuclear waste treatment programs in the United States to the Nuclear Waste Treatment Program (NWTP) at Pacific Northwest Laboratory (PNL). A principal program objective is to establish relationships between vitrification process control and glass product quality. Users of the liquid-fed ceramic melter (LFCM) process will need such relationships to qualify the waste for repository disposal. Target glass compositions have been formulated to obtain properties which minimize the chances of radioactive releases into the environment. The chemical durability of the glass product, which is a quality characteristic of particular interest with respect to acceptance of the glass at a licensed Federal repository, can be estimated from the composition of the product. The NWTP proposed that compliance with product specifications pertaining to the waste form be shown primarily by demonstrating that a certain glass composition is maintained; therefore the uncertainty in the composition and in the process behavior that can affect the composition must be well understood.

DOE's Office of Geologic Repositories has instituted a Waste Acceptance Process "to outline the documentation and activities required to ensure that waste forms, other than spent fuel, will be acceptable at any of the potential repositories." (a) A Waste Acceptance Committee (WAC) has been established to implement this process.

(a) "Establishment of Waste Acceptance Process and Waste Acceptance Committee." Memorandum from W. J. Purcell, U.S. Department of Energy, July 8, 1985. 
The purposes of the WAC are "to concentrate repository project and waste producer contractor resources to focus on the development of waste acceptance requirements, specifications, and other related documentation to advise" the DOE. (a) The WAC is responsible for reviewing certain documents called for by the Waste Acceptance Process; the principal documents are (1) a Waste Form Description, (2) a Waste Acceptance Preliminary Specification, (3) a Waste Form Compliance Plan, and (4) a Waste Form Qualification Report.

Documents (1), (3), and (4) are developed by the waste producer projects. The Waste Form Compliance Plan must describe how a waste producer proposes to comply with the Waste Acceptance Preliminary Specifications. The Waste Form Qualification Report must describe how the producer has shown that the proposed compliance methods have been successfully demonstrated.

It is common in the manufacturing industry to determine product quality through contact inspection after product completion; often this involves destructive examination. If a batch of product is found to be defective, it could be recycled through the process, relegated to scrap, or shipped under a lesser specification (i.e., a "factory second"), depending on the situation. These kinds of quality control approaches are not feasible for a process manufacturing canisters of vitrified high-level nuclear waste. Once manufactured, the canisters must be acceptable for disposal in a licensed geologic repository. It would be prohibitively difficult to recycle the glass back into the vitrification process. None of the product can be treated as scrap; and there is no alternative.

Moreover, it would be undesirable to examine a canister destructiveiy in order to obtain a glass sample. Sampling other than through an open canister at the top surface of the glass (which would be difficult) would require coring through the canister wall and into the glass. This process would leave a void in the glass and would require repair of the canister wall. Part of the waste acceptance specifications pertains to quality assurance of the closure weld. Thus, coring into the canister would require that this specification be addressed for a plug weld as well, a very difficult task compared to the

(a) "Establishment of Waste Acceptance Process and Waste Acceptance Committee." Memorandum from W. J. Purcel1, U.S. Department of Energy, July 8, 1985. 
relatively well-controlled welding processes (electrical resistance, flywheel/inertial) being considered for the top closure of a canister. Finally, facilities, equipment, and laboratories would have to be provided at additional cost (and perhaps additional worker exposure) to conduct analyses on the glass.

A desirable and feasibie alternative to destructive examination of canisters is correlation of the quality of the glass product with information obtained during monitoring and control of the process. This report presents a widely used and accepted industrial manufacturing method of quality control which is applicable to the production of nuclear waste glasses. The method known as Statistical Process Control (SPC) can be used not only to monitor the waste glass manufacturing process but to aid in understanding and improving the process. Statistical Process Control can be an important means of denonstrating in a Waste Form Qualification Report that a vitrification process can be controlled sufficientiy to consistently produce an acceptable product, and that when produced, the product will be characterized sufficiently to compare it with the Waste Acceptance Preliminary Specification. In particular, SPC can be an effective means of providing confidence in the quality of waste glass outside those close to the process. Examples of successful SPC applications in other industries are presented along with a discussion on the theoretical basis for SPC. Applications specific to the waste glass production process are demonstrated. These applications address sampling considerations, detectability of process upsets, and decisions affecting product quality. 


\subsection{STATISTICAL PROCESS CONTROL}

Statistical Process Control (SPC) is a method for monitoring and controlling a process which is affected by random inherent variations. In the early 1900s, SPC was established (largely by WA. Shewhart of Bell Telephone Laboratories) as an effective method for quality control. The practice of SPC was not widely received until after World War II, when the Japanese became interested in implementing SPC practices to improve the extremely poor quality of products manufactured there. Dr.W. E. Deming, a statistician trained in the area of SPC, made a tremendous contribution to the acceptance of quality control by giving special lectures to the representatives of major Japanese industries. The coveted Deming Prize for quality control was later established in Japan to commemorate his contribution; it is awarded to individuals and companies who have realized significant improvements through SPC. By implementing Deming's management philosophy and using SPC to aid in quality improvement, the Japanese have substantially improved manufacturing quality (Deming 1982).

In recent years, industry in the United States has begun to impiement quality control programs similar to those developed by the Japanese, in order to remain competitive. Deming and others have served as consultants to top management of various large companies; moreover, Deming's seminars are widely attended. The use of SPC in American companies has received substantial publicity through a national television documentary, (a) a Business Week cover story (Business Week 1979), a Deming fiTm, (b) and other video tapes of successful applications of SPC in industry (Nelson 1982; MIT Video Series).

\subsection{APPLICATIONS IN U.S. INDUSTRY}

Successful applications of SPC in American industry are numerous. Ford Motor Company has an extensive quality control program in place where time and effort are devoted to training personnel in the use of statistical tools for quality improvement (Ford Motor Company 1984). The Pontiac Motor Division of

\footnotetext{
(a) The documentary, produced by NBC TV in 1981, was entitled "If Japan Can, Why Can't We?"

(b) Deming, W. E. "Road Map for Change--The Deming Approach." Encyclopaedia Britannica Educational Corp., Color FiTm, No. 02-3889.
} 
General Motors trained employees in SPC practices before opening their new Fiero plant. A film, "Road Map for Change," depicts the implementation and benefits of SPC in that plant. These motor companies are realizing savings, along with improved processes and products, as they increase their understanding of their processes and the variables affecting product quality.

The RCA Corporation recently devoted an entire issue of RCA Engineer, a technical journal for RCA employees, to the application of SPC within RCA. Throughout the publication were numerous examples of improved quality as a result of SPC implementation. Phrases such as "...decreased line scrap five percent," "...threefold reduction in defects," "...variability due to setup was drastically reduced" appear throughout the publication (RCA Engineer 1985).

Signetics Corporation produces integrated circuits built on silicon wafers. They found that the amount of rework limited their production level. Through implementation of SPC, many of the manufacturing problems were eliminated, resulting in increased productivity and improved quality (Butler 1986). A necessary ingredient to quality improvement was training of production personnel in SPC techniques and team work between production personnel, management, and statisticians.

Many more examples can be found throughout the literature. A partial listing of additional case studies where SPC was implemented in industry is provided in the reference section of this report. Companies implementing SPC include American Telephone and Telegraph (AT\&T), International Business Machines (IBM), the NEC Corporation, Westinghouse, DuPont, and countless others. As B. Joiner, President of Joiner Associates Consuiting Firm, points out, "SPC is a tool being used to transform North American industry" (Joiner 1985). The technique is widely used and well established for monitoring and improving the quality of a process. It has become the standard method for quality control and improvement throughout industry.

\subsection{THE SPC METHOD}

Basic to SPC is the concept that in the manufacture of any product, including waste glass, measurements or characterizations of the product or the process variables exhibit inherent variation due to unintentional process changes and random chance mechanisms. Even when an attempt is made to control 
the process (for example, to control the melter feed composition in an LFCM process), ongoing measurements of the process will reveal this inevitable process variation even though all components are operating properly. One corporation president suggests that the fajlure to understand variability is one of the major problems facing American industry today (Nelson 1982). Decisions must be made in the presence of the uncertainty resulting from variability.

SPC is a procedure for monitoring the process in the presence of natural uncertainty and producing information about the process that can be used to make decisions. Under SPC, the inherent expected variation is allowed, whereas shifts or variances above those expected under normal operating conditions are detected. Typically, the average measured value and the variability of the process characteristic to be controlled are both used to assess process control.

SPC techniques can be applied to any process output. "Process output" can be defined as not only the product that is produced, but also the intermediate outputs that describe the operation state of the process. For example, in the LFCM process these intermediate outputs may be such characteristics as temperatures, feed compositions, and tank level indications. When interpreted correctly with the help of SPC techniques, accumulated information can be used to decide whether action is necessary to correct the process. If such information is used only to tag and identify a defective product rather than to correct the process, no assurance of quality nor achievements toward improved quality will be accomplished.

Because SPC is based on the jdea of variation, one must realize that there are many sources of variation which affect a process. Distinguishing between common causes and special causes of variability is helpful. "Common causes" refer to the many sources of variation affecting a process that is in statistical control. All combined common-cause variations form a pattern that can be characterized by a distribution. Special-cause variations are not part of the process and present themselves in unpredictable ways. In the LFCM process, for example, a common-cause variation might be the inherent lack of precision 
associated with the mechanism used to measure the level of the material in a tank, whereas a special-cause variation may be due to a plugged glass former feed line.

Only when a process is in statistical control can one predict the level and variability of the process parameters; statistical control is the key to predicting waste glass quality characteristics. A process is in statistical control only when there are no special-cause variabilities present. Deming points out that statistical control is not a natural state for most manufacturing processes. It is achieved only by a determined effort to eliminate special causes of excessive variation (Deming 1975). Initially, SPC aids in eliminating the special causes of variation, thereby bringing the process into statistical control. This refinement provides predictability to waste glass characteristics. However, statistical control does not assure high quality. Further improvements in quality may be achieved by isolating and decreasing the major sources of common-cause variation; SPC helps to isolate and characterize these sources of variation.

\subsection{CONTROL CHARTS}

Numerous SPC tools exist, such as flow diagrams, cause/effect diagrams, and pareto charts, that are simple yet very effective for quality improvement. However, to demonstrate the application of SPC to the waste glass process, only control charting is employed in this report. Shewhart control charts are major SPC tools. These include charts for averages, standard deviations, ranges, and proportions. Control charts are constructed by defining limits which help determine whether the charted values (process averages and variances) are being affected by Tevels of random variations (Grant and Leavenworth 1980).

The statistical theory of control charts is founded on the central limit theorem. This theorem states that the form of the probability distribution of sample means approaches the form of a normal probability distribution as the size of the sample is increased, regardless of the distribution describing the individual samples used to calculate the sample means. For a normal distribution, $68 \%$ of values selected randomly will fall within \pm 1 standard deviation of the mean, $95 \%$ fall within \pm 2 standard deviations, and $99.7 \%$ within \pm 3 standard 
deviations. The Shewhart control chart establishes control limits at \pm 3 standard deviations from the mean of a process variable being monitored. The process mean and standard deviation must be specified as required values or determined either from past or simulated data when the process is considered to be in statistical control, during which time $99.7 \%$ of the measurements should fall within the process control limits. Measured values that fall outside these limits are taken as evidence that the corresponding fluctuations are not part of the acceptable random fluctuations inherent in the process; the process has been altered and is determined to be out of statistical control.

The control chart is a method for determining whether process fluctuations are due to inherent process variability and require no special action by the operator or management, or result from special-cause variabilities which should be examined, isolated, and corrected to bring the process back into control. Isolation and elimination of special-cause variability is vital in the LFCM process. It is possible to predict waste glass characteristics only when the process is in statistical control, free from all special-cause variations. 


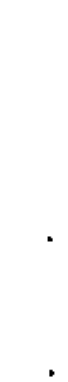




\subsection{IMPLEMENTING SPC ON THE LIQUID-FED CERAMIC MELTER (LFCM)}

The production of nuclear waste glass is similar in many ways to the manufacturing of numerous diverse products. The process is to be monitored over time to determine and control product quality. There will be special and common causes of variation. The customers (the public and repositories) demand a quality product. Although it is impractical to monitor the final product, many intermediate outputs can be examined. SPC could be implemented at various stages of the LFCM process. Control charts could be implemented at each tank, on much of the instrumentation, on laboratory controls, etc.

For demonstration purposes, this report focuses on the application of control charts to the feed sample composition determined through sampling and analysis of a feed preparation tank. A simplified flow diagram of a generalized LFCM vitrification system is shown in Figure 1 . There are five major tanks in the system: the Waste Lag Storage Tank (WLST), Waste Concentration Tank (WCT), Feed Preparation Tank (FPT), Melter Feed Tank (MFT), and the melter. The first four tanks are assumed to be well-agitated and thus ideally mixed.

Briefly, the flow of material through the system is as follows. Dilute waste slurry is periodically batched to the WLST. From there it is transferred to the WCT, where the slurry is concentrated, by evaporation, to less than onefourth the original volume. Once the slurry has been adequately concentrated, it is transferred to the FPT, where glass formers are added and additional evaporation occurs. After the slurry has been adequately concentrated in the FPT, it is transferred to the MFT, which in turn is continuously fed into the melter.

In order to determine the amount of glass formers to add to the waste constituents in the FPT, the composition of the waste must be determined. This is accomplished by sampling each WLST batch. The accuracy and precision of composition estimates of the siurry in the WLST will depend on how many samples are taken and how many analytical determinations are made on these samples. Various sampling strategies are possible, ranging from a single analys is on a single sample to replicate analyses of replicate samples. Obviously more 


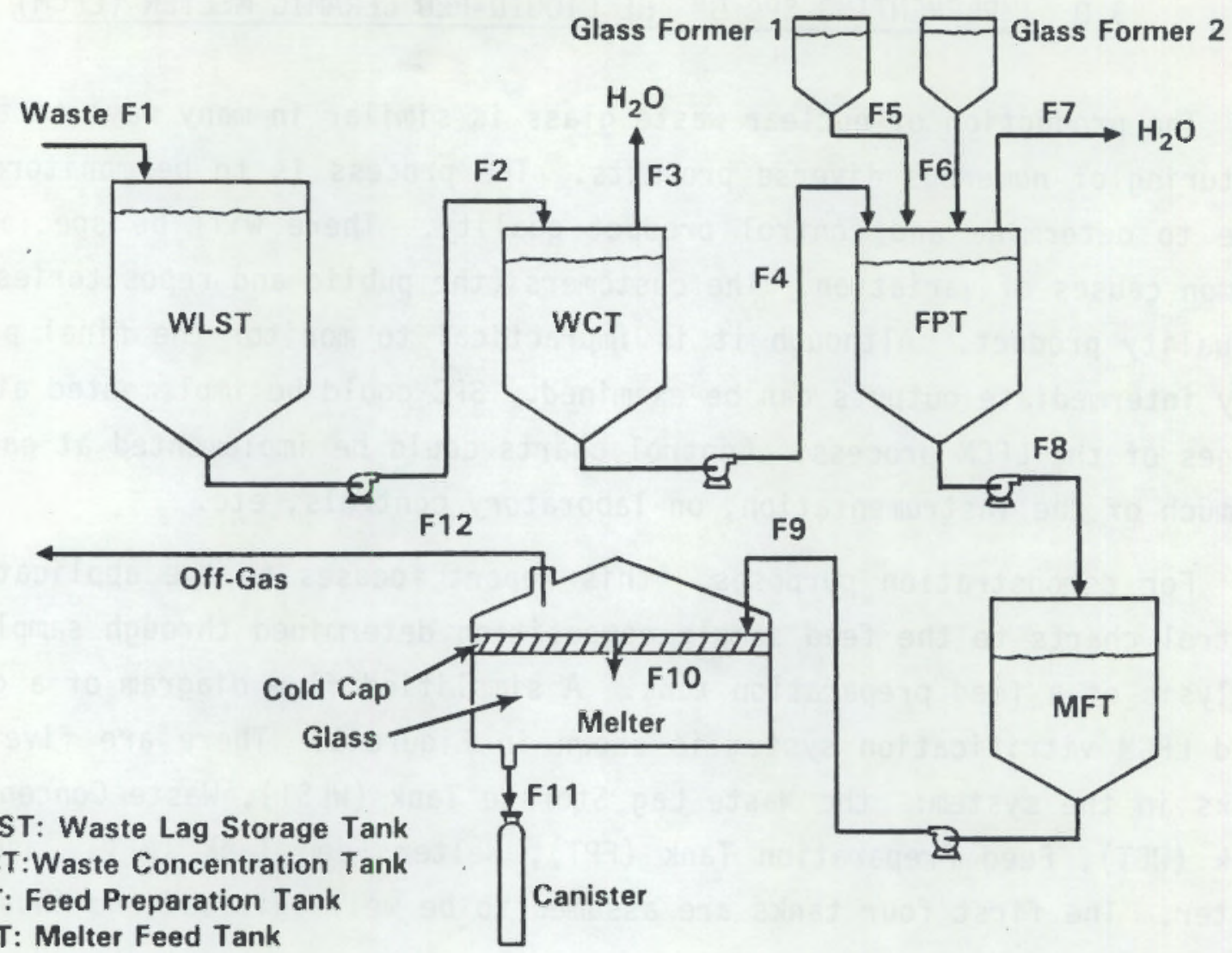

FIGURE 1. Flow Diagram of the LFCM Vitrification System

samples and more analyses will provide a more precise estimate of the true composition. The average WLST waste composition for a given batch would be used to determine the amount of glass formers to add in the FPT.

It is assumed that a sample (or samples) of the combined waste and glass former feed slurry will be taken in the FPT prior to transfer to the MFT. This will measure the proximity of the feed to the target composition.

Three major sources of common-cause variability affect the apparent FPT average composition. The first is sample-to-sample differences. Some variability exists among replicate samples taken from the same FPT batch. This component may be reduced by adequate mixing in the tank, but variabilities associated with preparing the sample for analysis will still exist. The second source of variation is analytical variability. Differences will exist between replicate analyses of the same sample. The third source is inherent process variability, caused by variations in such factors as tank level measurements, 
frit additions, and the measured WLST composition (which drives the frit addition). The magnitudes of the sampling and analytical sources of variation will affect the difference between the true and measured compositions of the FPT, whereas the magnitude of the process variation will affect the difference between the target composition and the true composition.

Estimates of sampling and analytical variation can be obtained from laboratory data and previous experience with similar LFCM samples. Because the combined effect of all sources of variability contributing to the overall process variation is difficult to quantify, the process variability is best estimated by running the process, or by simulating a run of the process when it is in control. A simulation requires that all major sources of variation contributing to the overall process variation be determined. Such a simulation has been attempted as a demonstration of an approach to waste form qualification (Reimus et al. 1986). 


\subsection{APPLICATION OF CONTROL CHARTS TO SIMULATED FPT AVERAGE COMPOSITIONS}

The specific application of control charting in this demonstration is integral to the specifics of the simulated process outlined in Figure 1. Each time the WLST is filled, the composition of the incoming waste mix is randomly selected from a normal distribution of possible waste mix compositions. The apparent waste and heat concentration in the WLST (after filling) is used in the glass former addition algorithm to determine the amount of glass formers to add to two successive batches of feed made up in the FPT (one batch in the WLST is the volume equivalent of two batches in each of the WCT and the FPT).

To simplify the simulation for the demonstration, the combined waste and glass former composition was limited to the constituents 1 isted in Table 1. These include five constituents: $\mathrm{Na}_{2} \mathrm{O}_{2} \mathrm{~B}_{2} \mathrm{O}_{3}, \mathrm{SiO}_{2}$, frit and water; the balance of the process stream is categorized into either "heat producers," "other waste," or "other glass formers." FPT compositions were simulated for ten runs of $4000 \mathrm{hr}$ per run. The simulated FPT composition was obtained before adding FPT sampling and analytical variability. Thus, the variability between simulated FPT compositions reflected only the process variation (differences between the true and target compositions).

The waste glass process has characteristics that set it apart from common applications of control charts. When a tank is ready to be filled, it contains a heel remaining from the previous tankful. This heel causes a correlation

TABLE 1. Target Compositions of FPT Feed and Glass (mass fractions)

\begin{tabular}{lll} 
Constituent & \multicolumn{1}{c}{$\begin{array}{c}\text { FPT } \\
\text { Feed } \\
\text { Target }\end{array}$} & \multicolumn{1}{c}{$\begin{array}{c}\text { Glass } \\
\text { Target }\end{array}$} \\
\cline { 2 - 3 } Heat Producers & 0.0027 & 0.00844 \\
Other Waste & 0.0928 & 0.290 \\
$\mathrm{~B}_{2} \mathrm{O}_{3}$ & 0.02917 & 0.0912 \\
$\mathrm{SiO}_{2}$ & 0.1507 & 0.47 \\
$\mathrm{Na}_{2} \mathrm{O}$ & 0.0225 & 0.0703 \\
Frit & 0.0225 & NA \\
Water & 0.68 & NA
\end{tabular}


between the previous tank composition and the current tank composition. In addition, there is some correlation between two FPT batches made from the same WLST batch. In the usual application of control charts, the assumption of independence of charted observations is required. In this demonstration, the correlation due to tank heels was decreased (but not eliminated) by obtaining FPT compositions after removing the effect of the heel composition from the previous FPT batch.

These simulated FPT compositions were studied to determine the effects of the above-mentioned correlations. The statistical technique of autoregression (Judge et al. 1982) was applied to examine the correlation structure of data produced over time. Autoregression is used to determine the dependence of the next deviation from the target composition in the FPT on previous deviations. For example, if the heat producers were higher than the target value for previous FPT batches, because of the heel remaining in the WCT from the previous batch, the next FPT batch might show a high value for heat producers if the autocorrelation were large. The degree of dependence on previous batches is characterized by the autocorrelation coefficient $(p)$. Applying this technique to the simulated data revealed that a first-order autoregressive model adequately described the correlation structure for the boron, silicon, and sodium oxides. However, there appeared to be no significant correlation $(\rho=0)$ over time for heat producers and other waste. This suggests that the usual control chart methods may be applied to the heat and waste compositions where the process variance, $S_{p}^{2}$, of an individual FPT batch average is calculated as follows:

$$
s_{p}^{2}=\sum_{i=1}^{n} \frac{\left(y_{i}-\bar{y}^{2}\right)^{2}}{n-1}
$$

where the $y_{i}$ are the individual FPT batch averages, and $\bar{y}$ is the overall average of the individual batch averages. 
The method for calculating the process variance for the boron, silicon, and sodium constituents requires additional attention. The variance of an observation with the correlation structure of a first-order autoregressive model is

$$
\sigma_{p}^{2}=\frac{\sigma_{v}^{2}}{1-\rho^{2}}
$$

where $\sigma_{v}^{2}$ is random variance and $\rho$ is the correlation between the current observation and the previous observation. The estimates of $\sigma_{v}^{2}$ and $\rho$ are easily obtained from simulated data for each constituent. If the variance of the $n$ data points for each constituent were calculated as in Equation (1), then it can be shown that the value of $s_{p}^{2}$ on the average tends to estimate

$$
s_{p}^{2}=\sigma_{p}^{2}\left(1-\frac{2 p}{n}\right)
$$

When $S_{p}^{2}$ is obtained from simulated data, $n$ is sufficiently large that

$$
s_{p}^{2}=\sigma_{p}^{2}=\frac{\sigma_{v}^{2}}{1-p^{2}} .
$$

Because $s_{p}^{2}$ incorporates information about the correlation structure and is an estimate of the process variance of an individual FPT batch average, it can be used to set up the control limits for individual FPT batch averages of boron, silica, and sodium as well as heat and waste compositions.

Up to this point, the variance discussed has excluded the sampling and analytical variances, $s_{s}^{2}$ and $s_{a}^{2}$, respectively. These variances are incorporated into the total variability as follows:

$$
s_{\text {Tot }}^{2}=s_{p}^{2}+\frac{s_{s}^{2}}{n_{s}}+\frac{s_{a}^{2}}{n_{a} n_{s}}
$$


where $n_{s}$ is the number of samples taken from each FPT batch and $n_{a}$ is the number of analytical determinations per sample. Control limits for the FPT batch averages for each constituent (including heat and waste compositions) could be calculated by

$$
\bar{Y}_{i} \pm 3 \sqrt{S_{\text {Tot }_{i}}^{2}}
$$

where $\bar{Y}_{i}$ is the overall average composition for the $i^{\text {th }}$ constituent (in the simulation $P_{i}$ is the target composition). When the apparent FPT composition for any constituent falls outside either control limit developed for that constituent, the process is considered to be out of control.

\subsection{CONSTRUCTING THE CONTROL CHART}

For illustrative purposes, a control chart for boron feed composition was constructed by applying Equations (5) and (6) to the simulated data from one 4000-hr melter run (see Figure 2). One sample was obtained from the WLST, and one analytical determination was made on that sample. The FPT sampling scheme used also consisted of one sample and one analysis per sample. The sampling

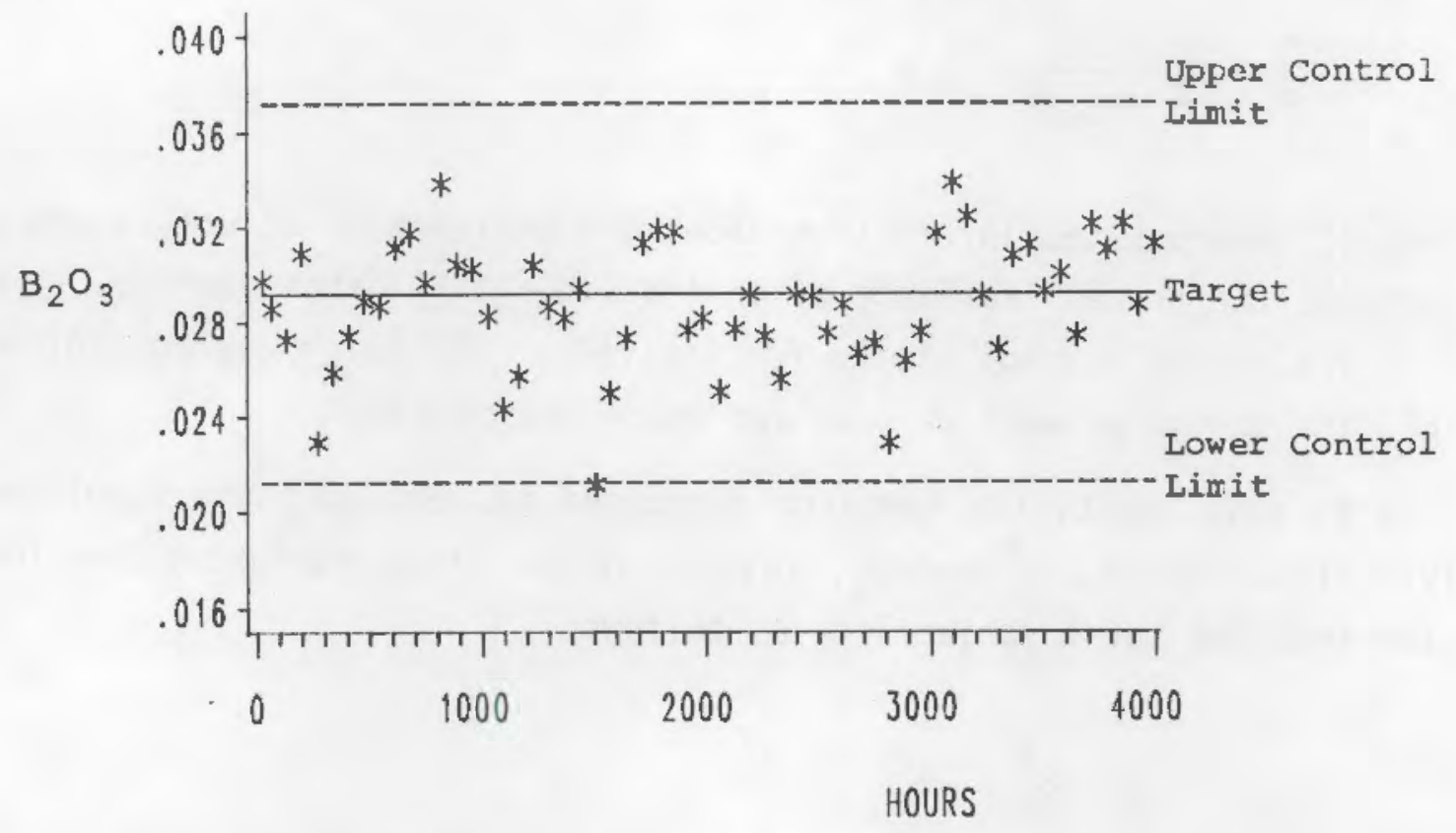

FIGURE 2. Control Chart of Simulated Boron Feed Composition 
and analytical standard deviations were each assumed to be $4 \%$ of the target boron composition. The dashed lines in Figure 2 are the control limits, and the solid line is the target boron composition. None of the simulated observations (with one possible exception) fall outside the control limits because the simulation was set up to be a process in statistical control.

This control chart is for individual FPT batches instead of the average of several batches. The central limit theorem, which states that the probability distribution of sample means approaches the form of a normal distribution regardless of the distribution of individual samples, does not apply here because the individual FPT batch is only one sample (not an average of several batches) from the population of FPT batches. When this theorem cannot be applied, application of the normal probability control chart techniques requires the strict assumption that individual FPT batches are from a normal distribution. The simulated data were checked to determine whether individual FPT batches were normally distributed. For this case, the assumption of normality appeared to be true.

The approaches for setting up a control chart require at least ten observations. Many vitrification projects may be limited by the number of FPT batches, and most are interested in obtaining information concerning product quality near the beginning of processing. To set up initial control charts, it would be wise to estimate inherent process variation on the basis of simulated data, and to estimate sampling and analysis variances on the basis of previous experimental data.

\subsection{UPDATING CONTROL LIMITS FROM ACTUAL PROCESS DATA}

It may be that process variation estimates obtained from simulation runs do not reflect reality. If this is the case, variance estimates should be updated by means of actual process data. Statistical analysis of variance techniques must be used to ferret out from the actual data the estimates of the three major sources of common cause variability mentioned above.

The appropriate estimate of the process variation to be used in setting the control limits is $\sigma_{p}^{2}$. With simulated data one can estimate $\sigma_{p}^{2}$ using $s_{p}^{2}$, 
because $n$ (the number of FPT batches) is large. However, when actual data are used, $n$ will probably be small. Thus, from Equation (3) an estimate of $\sigma_{p}^{2}$ is

$$
\sigma_{p}^{2}=\frac{s_{p}^{2}}{1-2 p / n}
$$

From Equation (5), the control limits about the process average would be calculated by

$$
\gamma_{i} \pm 3 \sqrt{\frac{s_{p}^{2}}{1-2 p / n}+\frac{s_{s}^{2}}{n_{s}}+\frac{s_{a}^{2}}{n_{s} n_{a}}}
$$

No other modifications are needed to update the average chart. 


\subsection{QUALITY CONTROL CAPABILITY AND SAMPLE SIZE STUDIES}

If the feed composition has shifted because of some failure or change in upstream processing, it is important to detect that shift quickly if it is large enough to significantly affect the glass quality. The ability of the proposed control charts to detect process shifts can be studied by examining the average run length of each chart. The average run length is the average number of observations plotted on a control chart after a process shift, before an out-of-control point is detected. The average run length depends upon a number of factors: the size of the shift in the process, the number of samples per FPT batch, the number of analyses per sample, and the process variability. Once estimates for the three major variance components are obtained, one could study the effects of varying the factors affecting the average run length of the control charts. This would provide insight into the sample sizes necessary to detect plausible shifts in the process.

Using the estimated inherent process variance from the simulation of the waste glass process and estimates of the sampling and analytical variability, the average run length was examined for three shift sizes, four combinations of the number of samples and analyses per sample from the FPT, and two sampling schemes from the WLST. The two sampling schemes from the WLST affect the process variability because the fewer samples or analyses obtained from the WLST, the more variability is introduced into the process by glass former addition. This examination was accomplished by simulating 1000 observations for each of the possible combinations of the factors on each constituent possessing a first-order autocorrelation structure (as determined from the analysis on the simulated process data).

A summary of the average run lengths for the control chart on FPT batch averages is presented in Table 2. The sample-to-sample standard deviation and the analytical standard deviation were each assumed to be $5 \%$ of the target value for the "heat producers" and "other waste" constituents and $4 \%$ for the $\mathrm{B}_{2} \mathrm{O}_{3}, \mathrm{SiO}_{2}$ and $\mathrm{Na}_{2} \mathrm{O}$ constituents. These estimates are conservative based on data reported in the letter report "Sampling Plan for the WVDP Feed Concentrator Make-Up Tank." (a)

(a) Bowen, W. M., and B. A. Pulsipher. 1985. Sampling Plan for the WVDP Feed Concentrator Make-Up Tank. MCC Letter Report to West Valley Demonstration Project. Pacific Northwest Laboratory, Richland, Washington. 
TABLE 2. Average Run Lengths

\begin{tabular}{|c|c|c|c|c|c|c|c|c|}
\hline \multirow[b]{2}{*}{ Component } & \multirow{2}{*}{\multicolumn{2}{|c|}{ WLST }} & \multirow[b]{2}{*}{$\begin{array}{l}\text { Percent } \\
\quad \text { Shift } \\
\end{array}$} & \multicolumn{5}{|c|}{ Average Run Lengths (d) } \\
\hline & & & & $\begin{array}{l}\mathrm{NS}^{(\mathrm{b})} \\
\mathrm{NA}(\mathrm{c})\end{array}$ & $\begin{array}{l}=1 \\
=1\end{array}$ & $\begin{array}{l}\text { NS }=1 \\
\text { NA }=3\end{array}$ & $\begin{array}{l}N S=3 \\
N A=1\end{array}$ & $\begin{array}{l}\text { NS }=3 \\
\text { NA }=3\end{array}$ \\
\hline $\begin{array}{l}\mathrm{B}_{2} \mathrm{O}_{3} \\
\mathrm{~B}_{2}^{2} 0_{3} \\
\mathrm{~B}^{2} 0_{3} \\
\mathrm{~B}^{2} 0_{3} \\
\mathrm{~B}^{2} 0^{3} \\
\mathrm{~B}_{2}^{2} \mathrm{O}_{3}^{3}\end{array}$ & $\begin{array}{l}1 \\
1 \\
1 \\
5 \\
5 \\
5\end{array}$ & $\begin{array}{l}1 \\
1 \\
1 \\
5 \\
5 \\
5\end{array}$ & $\begin{array}{l}10 \\
15 \\
25 \\
10 \\
15 \\
25\end{array}$ & $\begin{array}{r}>20 \\
>20 \\
3 \\
>20 \\
19 \\
1\end{array}$ & $\begin{array}{l}0 \\
0 \\
3 \\
0 \\
9 \\
1\end{array}$ & $\begin{array}{r}>20 \\
14 \\
2 \\
>20 \\
7 \\
1\end{array}$ & $\begin{array}{r}>20 \\
7 \\
2 \\
>20 \\
3 \\
1\end{array}$ & $\begin{array}{r}>20 \\
7 \\
2 \\
11 \\
3 \\
1\end{array}$ \\
\hline $\begin{array}{l}\mathrm{SiO}_{2} \\
\mathrm{SiO}_{2}^{2} \\
\mathrm{SiO}^{2} \\
\mathrm{SiO}_{2} \\
\mathrm{SiO}_{2} \\
\mathrm{SiO}_{2}\end{array}$ & $\begin{array}{l}1 \\
1 \\
1 \\
5 \\
5 \\
5\end{array}$ & $\begin{array}{l}1 \\
1 \\
1 \\
5 \\
5 \\
5\end{array}$ & $\begin{array}{l}10 \\
15 \\
25 \\
10 \\
15 \\
25\end{array}$ & $\begin{array}{r}>20 \\
>20 \\
8 \\
>20 \\
>20 \\
2\end{array}$ & $\begin{array}{l}0 \\
0 \\
8 \\
0 \\
0 \\
2\end{array}$ & $\begin{array}{r}>20 \\
>20 \\
6 \\
>20 \\
15 \\
2\end{array}$ & $\begin{array}{r}>20 \\
>20 \\
4 \\
>20 \\
9 \\
2\end{array}$ & $\begin{array}{r}>20 \\
18 \\
5 \\
>20 \\
6 \\
1\end{array}$ \\
\hline $\begin{array}{l}\mathrm{Na}_{2} \mathrm{O} \\
\mathrm{Na}_{2} \mathrm{O} \\
\mathrm{Na}_{2} \mathrm{O} \\
\mathrm{Na}_{2} \mathrm{O} \\
\mathrm{Na}_{2} \mathrm{O} \\
\mathrm{Na}_{2} \mathrm{O}\end{array}$ & $\begin{array}{l}1 \\
1 \\
1 \\
5 \\
5 \\
5\end{array}$ & $\begin{array}{l}1 \\
1 \\
1 \\
5 \\
5 \\
5\end{array}$ & $\begin{array}{l}10 \\
15 \\
25 \\
10 \\
15 \\
25\end{array}$ & $\begin{array}{r}>20 \\
>20 \\
8 \\
>20 \\
>20 \\
2\end{array}$ & $\begin{array}{l}0 \\
0 \\
8 \\
0 \\
0 \\
2\end{array}$ & $\begin{array}{r}>20 \\
>20 \\
6 \\
>20 \\
13 \\
2\end{array}$ & $\begin{array}{r}>20 \\
>20 \\
4 \\
>20 \\
8 \\
2\end{array}$ & $\begin{array}{r}>20 \\
>20 \\
4 \\
>20 \\
7 \\
2\end{array}$ \\
\hline $\begin{array}{l}\text { Heat } \\
\text { Heat } \\
\text { Heat } \\
\text { Heat } \\
\text { Heat } \\
\text { Heat }\end{array}$ & $\begin{array}{l}1 \\
1 \\
1 \\
5 \\
5 \\
5\end{array}$ & $\begin{array}{l}1 \\
1 \\
1 \\
5 \\
5 \\
5\end{array}$ & $\begin{array}{l}10 \\
15 \\
25 \\
10 \\
15 \\
25\end{array}$ & $\begin{array}{r}>20 \\
>20 \\
4 \\
>20 \\
>20 \\
4\end{array}$ & $\begin{array}{l}0 \\
0 \\
4 \\
0 \\
0 \\
4\end{array}$ & $\begin{array}{r}>20 \\
>20 \\
3 \\
>20 \\
>20 \\
2\end{array}$ & $\begin{array}{r}>20 \\
11 \\
2 \\
>20 \\
10 \\
2\end{array}$ & $\begin{array}{r}>20 \\
7 \\
2 \\
>20 \\
7 \\
1\end{array}$ \\
\hline $\begin{array}{l}\text { Waste } \\
\text { Waste } \\
\text { Waste } \\
\text { Waste } \\
\text { Waste } \\
\text { Waste }\end{array}$ & $\begin{array}{l}1 \\
1 \\
1 \\
5 \\
5 \\
5\end{array}$ & $\begin{array}{l}1 \\
1 \\
1 \\
5 \\
5 \\
5\end{array}$ & $\begin{array}{l}10 \\
15 \\
25 \\
10 \\
15 \\
25\end{array}$ & $\begin{array}{r}>20 \\
>20 \\
4 \\
>20 \\
>20 \\
4\end{array}$ & $\begin{array}{l}0 \\
0 \\
4 \\
0 \\
0 \\
4\end{array}$ & $\begin{array}{r}>20 \\
>20 \\
2 \\
>20 \\
>20 \\
2\end{array}$ & $\begin{array}{r}>20 \\
11 \\
2 \\
>20 \\
10 \\
2\end{array}$ & $\begin{array}{r}>20 \\
7 \\
2 \\
>20 \\
B \\
1\end{array}$ \\
\hline
\end{tabular}

(a) Percent shift is represented as a percent of the target elemental percentage shown in Table 1.

(b) NS is the number of samples obtained from each FPT batch.

(c) NA is the number of analyses performed per FPT sample.

(d) Large ARL values are not very accurate because the simulation contained only 1000 FPT batches. 
An examination of Table 2 reveals that 25\% shifts in the process average can be detected on a control chart within one to eight batches after the shift occurs, depending on the sampling scheme. If one is interested in detecting smaller shifts, either the number of samples or analyses must be increased, or variances due to the process, sampling, or analyses must be decreased.

In practice, the site-specific estimates of the variance components used to construct these control charts would be derived from previously collected data and/or simulations of the process. The estimates would be used to determine sampling schemes in the WLST and FPT that produced acceptable average run length values for detecting unacceptable process shifts. If the average run length values are unacceptable for every economically feasible sampling scheme, one must concentrate on eliminating some of the major sources of process, sampling, or analytical variation. This would be accomplished through statistical experimental design and SPC techniques applied to other steps in the processing, sampling, preparation, and analys is procedures. 


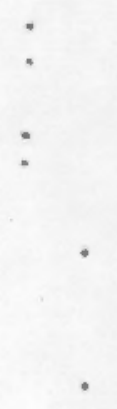




\subsection{SPC AS A GUIDE FOR FURTHER FEED ADJUSTMENTS}

The quality of the waste glass product can be improved by detecting and correcting process shifts through the use of control charts. The control charts are used to detect the special causes of variation. The ability to detect process changes is enhanced by increasing the number of samples taken (altering the sampling scheme) or by decreasing the common-cause variance. The ability to detect special-cause variations is enhanced when the common-cause variance is reduced; moreover, product quality is improved.

As shown earlier, there are three major sources of common-cause variability affecting the apparent feed composition. The first is the process variation, $\sigma_{p}^{2}$, which is a measure of the spread of the true FPT composition about the target composition. The other two sources are sampling and analytical variations. A plausible method for decreasing the difference between the true feed composition and the target feed composition (reducing the process variation, which in turn reduces common-cause variation) is to allow for an adjustment in the feed after the initial addition of glass formers. This step can be accomplished by holding the feed in the FPT until the results of the analysis of FPT samples from that batch are available. If the analysis shows a significant departure from the target composition, adjustments to the feed composition are made within that FPT batch before sending it to the MFT. The purpose of adjusting the feed composition is to decrease $\sigma_{p}^{2}$ by moving the true FPT composition nearer to the target composition.

The decision of whether adjustment of the FPT composition is needed is clouded by the fact that there is uncertainty in the estimate of the true FPT composition, due to sampling and analytical variations. Three decision rules are possible: (1) always adjust, (2) base the decision to adjust on SPC techniques, and (3) never adjust.

Always adjusting may not only prove costly in time and economics; in some cases, using this rule would actually increase $\sigma_{p}^{2}$ rather than decrease it. An extreme example magnifies the problem: Suppose that there is no process variability; the true FPT composition is always on target. Because of the sampling and analytical variation, the apparent FPT composition would nearly always be 
different than the target composition. As a result, the FPT composition would be adjusted. Then, $\sigma_{p}^{2}$ would increase, because adjustment has moved the true composition away from the target composition. Although this example is exaggerated, a similar increase of $\sigma_{p}^{2}$ would occur when the process variation is small relative to the combined sampling and analytical variance. This fact is demonstrated later.

A better decision rule would be based on SPC techniques. Adjusting should be done only when there is a high probability that the true FPT composition is different from the target composition. A control chart centered at the target composition could be established to detect differences between the target composition and the apparent composition that are greater than would be expected from sampling $\left(S_{s}^{2}\right)$ and analytical $\left(S_{a}^{2}\right)$ uncertainties. The control limits of this control chart would be

$$
\text { Target } \pm 3 \sqrt{\frac{s_{s}^{2}}{n_{s}}+\frac{s_{a}^{2}}{n_{a} n_{s}}}
$$

If an apparent FPT composition were to fall outside the control limits, adjustment would be necessary. If the apparent FPT composition were to fall within the limits, one could not be certain that the true FPT composition is different from the target composition, and no adjustment should be made.

The performance of the decision rule based on SPC was examined by simulating boron data with varying sampling and analytical strategies. Various values for the process variation were examined. The results of these simulations are shown in Figure 3. The process variation is represented as a standard deviation relative to the target boron concentration. The vertical axis represents the true process relative standard deviation after the adjustment (RSDA) decision rules are applied. The horizontal axis is the true process relative standard deviation before adjusting (RSDB). When there is no adjustment, the RSDB and RSDA are the same (producing a straight line on the plots). When one always adjusts, the RSDA is greater than the RSDB when the RSDB is less than the relative standard deviation for sampling and analysis. When the RSDB is greater than the sampling and analysis relative standard deviation, the true process relative standard deviation is always decreased by adjusting. The 
SAMPLES-1 ANALYSES-1
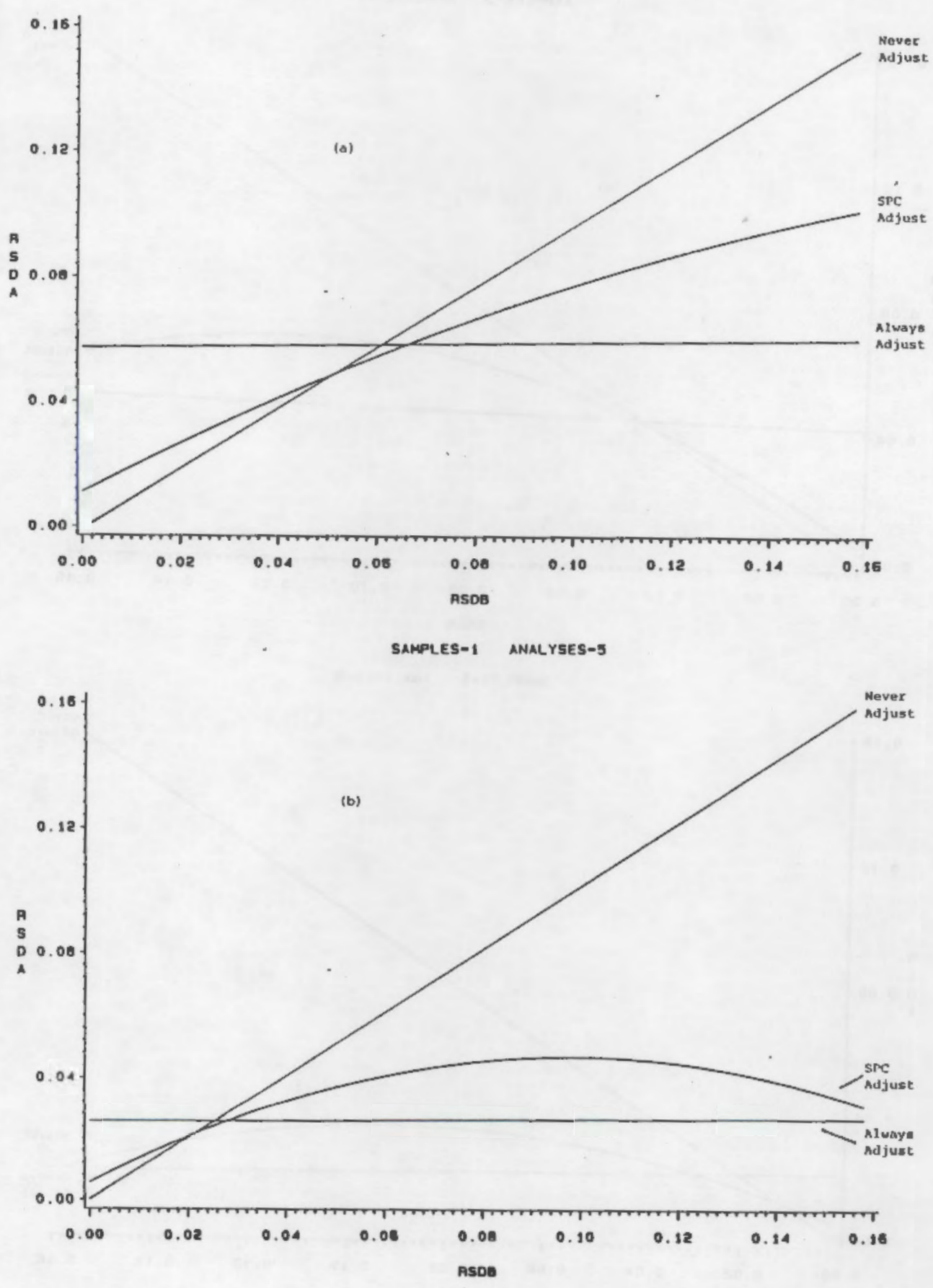

FIGURE 3. Comparison of Decision Rules for Adjusting Feed Composition. RSDA is the true process relative standard deviation after applying the adjustment decisions. RSDB is the true process relative standard deviation before applying the adjustment decisions. 
SAMPLES-5 ANALYSES-1

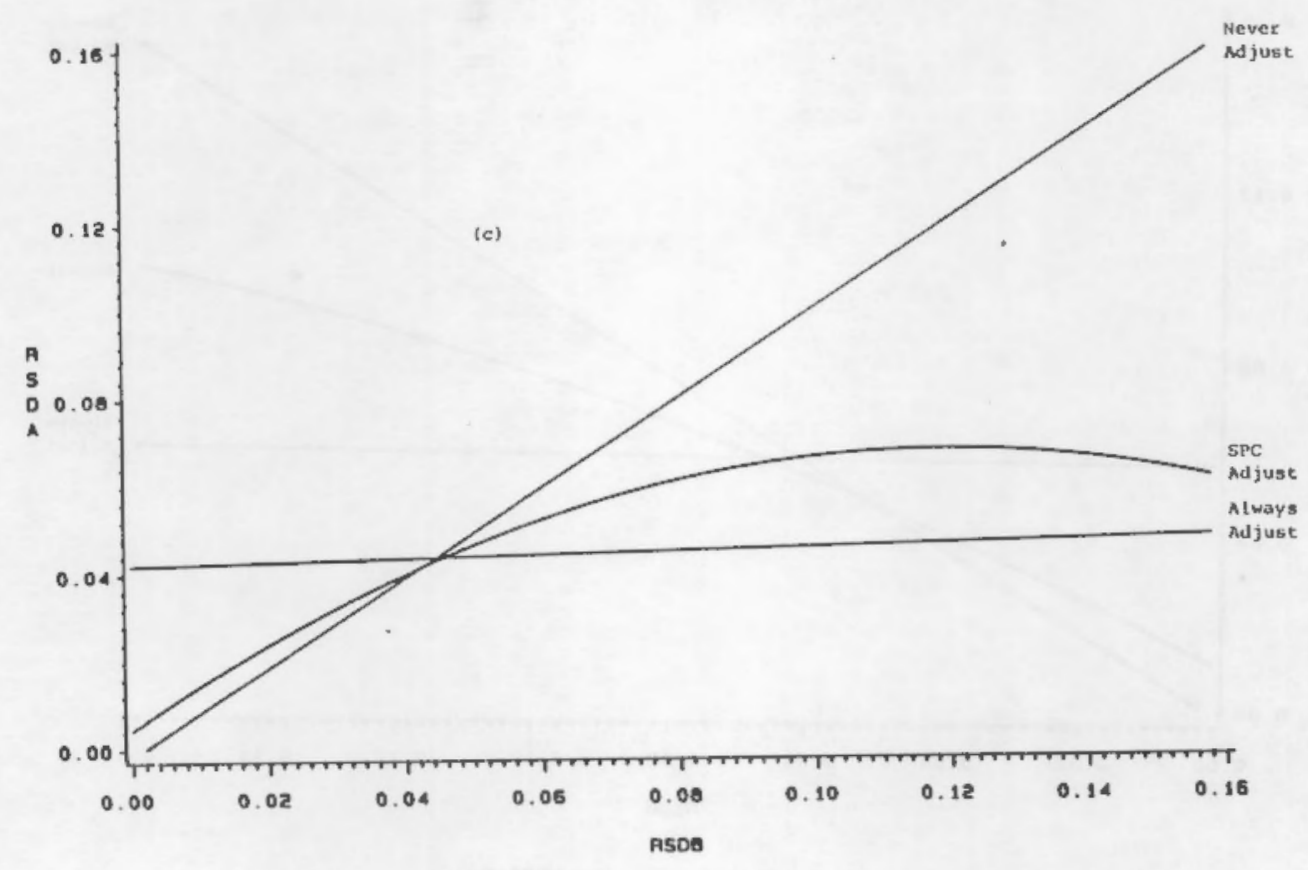

SAMPLES-5 ANALYSES-5

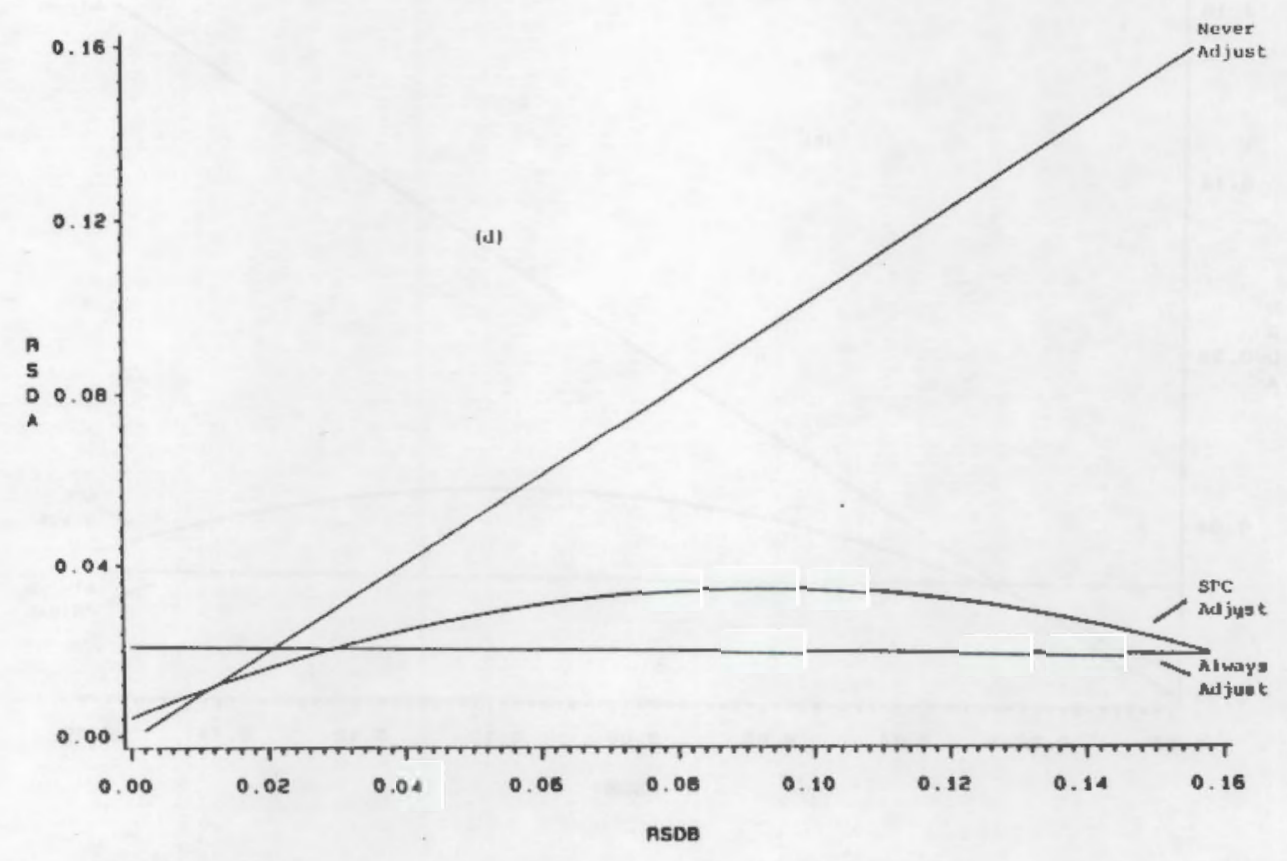

FIGURE 3 . (contd) 
decision rule based on SPC protects against adjusting when adjusting would only inflate the process variance. Furthermore, it protects agajnst not adjusting when adjustment is needed. This attribute is illustrated by the similarity of the RSDA values for the never-adjust and SPC-based rules when the RSDB is low, and by the similarity of the RSDA for the aiways-adjust and SPC-based rules when the RSDB is high.

$S P C$ is a valuable technique for decisions regarding feed composition adjustments. Without SPC, there is a chance of increasing rather than decreasing the variability of the true feed composition. Additional studies could be performed to determine the best SPC decision rule from the desired probabilities of making the correct decision for adjustment. 


.




\subsection{CONCLUSIONS AND RECOMMENDATIONS}

Statistical Process Control is becoming a standard industrial practice in the United States for monitoring and controlling the quality of products. It has proven itseif, in the Japanese market as a vital tool for quality improvement. Many large U.S. companies are beginning to reap the benefits of SPC. Its power is in providing guidance to the decision-making process in the midst of uncertainty (variability).

Statistical Process Control can be applied to the LFCM process to provide guidance for decisions concerning required sample sizes, quality of product, changes in the process, and adjustments to the feed composition. It could be a tool for improving the quality of the waste glass through a better understanding of the factors affecting the process. Many SPC tools exist and could be applied throughout the waste glass production system. Control charts on the FPT batch compositions have provided one example of SPC applied to the LFCM process.

The SPC techniques are tangible and easily understood. Control charts can easily be programmed on a computer for both internal and external use. In addition, multivariate control charting techniques, which offer the capability of studying the multidimensional region associated with the simultaneous examination of all constituents, could be programmed. Multivariate control charts examine the Euclidean distance from the overall centroid (target composition) and flag values which are "too far away" from that centroid. Shewhart control charts are not the only SPC tools. Other tools such as Cusum charts could possibly be more powerful for detecting process shifts.

This demonstration has focused on feed-slurry samples. However, implementation of SPC at an earlier stage in the process may provide more rapid detection of a process upset, thereby providing enough time to adjust the feed before going into the melter. Hopefully, SPC could be applied throughout the process with SPC on the end feed product as a minimum expectation. Focusing on the preceding steps of the process might prove more beneficial in the long run. Sensitivity analyses could be run to determine the effect of decreasing upstream sources of variation on the uniformity and quality of the product. 
These upstream sources of variation could be monitored by SPC techniques. In effect, SPC could be used throughout the process to monitor and improve the LFCM process. 


\subsection{REFERENCES}

Business Week. 1979. "American Manufacturers Strive for Quality--Japanese Style." March 12 (cover story).

Butler, C., and G. R. Bryce. 1986. "Implementing SPC with Signetics Production Personnel." Quality Progress 19(4). American Society for Quality Control, Milwaukee, Wisconsin.

Deming, W. E. 1982. Quality, Productivity, and Competitive Position. Massachusetts Institute of Technology, Cambridge, Massachusetts.

Deming, W. E. 1975. "On Some Statistical Aids Toward Economic Production." Interfaces, Vol. 5, No. 4, August 1975, The Institute of Management Sciences, Providence, Rhode Island.

Ford Motor Company. 1984. Continuing Process Control and Process Capability Improvement. Statistical Methods Office, Ford Motor Company, Dearborn, Michigan.

Grant, E. L., and R. S. Leavenworth. 1980. Statistical Quality Control. McGraw-Hi11, New York.

Joiner, B. L. 1985. "The Key Role of Statisticians in the Transformation of North American Industry." The American Statistician, Vol. 39, No. 3, August 1985, American Statistical Association, Washington, O.C.

Judge, G. G., et al. 1982. Introduction to the Theory and Practice of Econometrics. Wiley $\delta$ Sons, New York.

MIT Video Course. "The Deming Videotapes: What America's Managers Must Do To Improve Quality, Productivity and Competitive Position." Massachusetts Institute of Technology, Cambridge, Massachusetts.

Nelson, L. S. 1982. "Nashua Corporation's Statistical Quality System." Paper presented at the Annual Meetings of the American Statistical Association, Cincinnati, Ohio.

RCA Engineer. 1985. Vol. 30, No. 3, RCA Technical Excellence Center, Princeton, New Jersey.

Reimus, P. W., et a1. 1986. Demonstration of an Approach to Waste Form Qualification Through Simulation of LFCM Process Operations. PNL-5919, Pacific Northwest Laboratory, Richland, Washington. 
. 


\subsection{ADDITIONAL CASE STUDY ARTICLES AND COLLECTIONS RELATED TO SPC}

American Society for Quality Control. 1985. Quality Progress 18(6).

Anderson, R. W., and A. W. Wortham. 1958. "An Application of Variance Component Analysis in the Transistor Industry." Industrial Quality Control $14(9): 11-15$.

Armstrong, J. A., Jr. 1956. "Some Uses of Statistics in Plant Maintenance." Industrial Quality Control 12(7):12-17.

Bass, L. 1957. "Make It Right the First Time." Industrial Quality Control $13(11): 35-42$.

Benz, W. M. 1967. "Quality Control in the Office." Industrial Quality Control 23(11):531-534.

Bingham, R. S., Jr. 1958. "A Guide to the Use of Statistics in the Chemical Industry." Industrial Qual ity Control 15(3):14-18.

Burgham, P. M. 1985. "Design of Experiments, the Taguchi Way." Manufacturing Engineering. 94(5):44-47.

Caplan, F., Jr. 1958. "Process Control in a Job Shop." Industrial Quality Control 15(5):16-18.

Chateauneuf, R. 1960. "Modern QC Pays Off in Woodwork." Industrial Quality Control $17(3): 19-25$.

Cheung, K. Y., W. S. Lindsay and D. J. Friedland. 1985. "A Statistical Study of Sources of Variation in Primary Battery Testing." J. Electrochemical Socjety $132(1): 1-5$.

Clifford, P. C. 1971. "A Process Capability Study Using Control Charts." J. Quality Technology 3(3):107-111.

Conne11, F. M., Jr. 1967. "Statistical Quality Control of Clerical Operations." Industrial Quality Control 24(3):154-162.

Daw, H. R. 1965. "Systematic Procedure of Trouble Spotting." Industrial Quality Control 21(9):443-449.

DeBusk, R. E. 1962. "Experience in EVOP at Tennessee Eastman Company." Industrial Quality Control 19(4):15-21.

Eichelberger, L. S. 1956. "Statistical Quality Control in a Press Shop." Industria] Quality Control 13(2):12-17.

Frey, W. C., and W. M. Spencer. 1958. "Automatic Statistical Filling Control, a Case History." Industrial. Quality Control 14(8):13-16. 
Fuller, F. T. 1984. "Fix the Process, Not the Product." Electronic Packaging and Production, 24(2):107-175.

Glasser, G. J. 1985. "Quality Audits of Paperwork Operations: The First Step Toward Quality Control." J. Quality Technology 17(?):102-109.

Hahn, G. J. 1982 "Statistical Assessment of a Process Change." J Quality Technology 14(1):1-9.

Hahn, G. J. 1984. "Experimental Design in the Complex World." Technometrics $26: 19-31$.

Hamaker, H. C. 1961. "Examples of Designed Experiments." Industrial Quality Control 17(9):16-20.

Hamlin, C. K. 1957. "Statistical Quality Control Methods at Rome Cable Corporation." Industrial Quality Control 14(2):8-16.

Harrison, H. R. 1956. "Statistical Quality Control Will Work on Short-Run Jobs." Industrial Quality Control 13(2):8-11.

Hill, W. J., and R. A. Wiles. 1975. "Plant Experimentation (PLEX)." J. Quality Technology 7:115-122.

Hinchen, J. D. 1956. "Correlation Analys is in Batch Process Control." Industrial Quality Control 12(11):54-59.

Hitzelberger, A. J. 1967. "Improve Your Reliability." Industrial Quality Control 24(6):313-316.

Hoffman, E. R. 1955. "Quality Control in Paper Finishing." Industrial Quality Control 12(5):7-12.

Kemworthy, 1. C. 1967. "Some Examples of Simplex Evolutionary Operation in the Paper Industry." Applied Statistics 16:211-244.

Langevin, R. G. 1977. Quality Control in the Service Industries. Argyle Associates, New Canaan, Connecticut.

Latzko, W. J. 1984. "The Paperwork Factory." Quality 23(3):31-33.

LeClair, T. G. 1958. "Quality Control in the Electric Service Industry." Industrial Quality Control 14(10):9-11.

Lindsay, W. S., and R. F. Picone. 1984. "Components of Variance Analysis: A Useful Statistical Technique for Analytical Chemistry." Analytical Letters 17(A15): 1731-1742.

Metals Technical Committee of ASQC. 1964. Case Histories on Statistical Methods for Quality Control Series III. American Society for Quality Control, Milwaukee, Wisconsin. 
Meyer, T. R., J. H. Zambone and F. L. Curcio. 1957. "Applications of Statistical Quality Control in Giass Fabrication." Industrial Quality Control 14(2):21-23.

Mueller, F.X., and D. M. 0lsson. 1971. "Application of Statistical Design for the Solution of Industrial Finishing Problems." J. Paint Technology $43: 54-62$.

Occasione, J. R. 1956. "Quality Control as Applied to Continuous Processes." Industriai Quality Control 13(4):9-13.

Ost]e, B. 1956. "Industry Use of Statistical Test Design." Industrial Quality Control 24(1):24-34.

Dtt, E. R., and R. D. Snee. 1973. "Identifying Useful Differences in a Multiple-Head Machine." J. Quality Technology 5(2):47-57.

Oxenham, J. P. 1957. "An Application of Statistical Quality Control Techniques to a Post office Processing Operation." Industrial Quality Control $14(3): 5-10$.

Phadke, M. S. 1982. "Quality Engineering Using Design of Experiments." Proceedings of the Section on Statistical Education. American Statistical Association, pp. 11-20.

Phadke, M. W., R. N. Kackar, D. V. Speeney, and M. J. Grieco. 1983. "Off-Line Quality Control in Integrated Circuit Fabrication Using Experimental Design." Bell System Technical Journal 62(5):1273-1309.

Prasad, C. R. 1982. Statistical Quality Control and Operational Research: 160 Case Studies in Indian Industries, Indian Statistical Institute, Calcutta, India.

Pringle, J. B. 1962. "SQC Methods in Telephone Transmission Maintenance." Industrial Quality Control 19(1):18-22.

Rogers, W. T. 1956. "Quality Control of Tubular Steel Products." Industrial Quality Control 13(2):6-11.

Snee, R. D. 1983. "Graphical Analysis of Process Variation Studies." J. Quality Technology 15(2):76-88.

Snee, R. D., L. B. Hare and J. R. Trout (eds.). 1985. Experiments in Industry: Design, Analysis and Interpretation of Results. Quality Press, Milwaukee, Wisconsin.

Von Osinski, R. 1962. "Use of Median Charts in the Rubber Industry." Industrial Quality Contro] 19(2):5-8.

Wadde11, J. J. 1961. "Quality Control in the Construction Industry." Industrial Quality Control 17(7):12-15. 
Wade, P. F. 1961. "The Use of Statistical Methods in Industrial Experimentation." Industrial Quality Control 18(2):5-9.

Walter, J. T. 1955. "Continuous Process Control in a Petroleum Refinery." Industrial Quality Control 12(6):5-7.

Ward, R. V. 1963. "SQC Applications in the Chemical Industries." Industrial Quality Control 20(1):4-8.

Way, C. B. 1961. "Statistical Quality Control Applications in the Food Industry." Industrial Quality Control 17(11):30-34.

Wilson, C. C. 1955. "Textile Quality Analysis." Industrial Quality Control $12(6): 14-18$.

Zimmerman, N. H. 1957. "Statistical Quality Control Applied to Precision Manufacture of Weapon Barrel." Industrial Quality Control 14(2):18-21. 


\subsection{ACKNOWLEDGMENTS}

The authors would like to thank Mitch Toland for his help in data analyses of simulation runs and the many insights he provided through discussions with the author. Al Liebetrau and Mike Bowen provided additional insights on applications of SPC in industry and to stochastic processes. Simulation data were provided by Paut Reimus. Additional thanks go to Sue Liebetrau for her editorial comments and suggestions. 


\section{DISTRIBUTION}

No. of

Copies

\section{OFFSITE}

30 DOE Technical Information Center

5 Geologic Repository Division DOE Office of Civilian

Radioactive Waste Management Forrestal Building Washington, DC 20585

ATTN: C. R. Cooley, RW-4

J. R. Hitley, RW-30

S. H. Kale, $\mathrm{RW}-20$

D. E. Shelor, RW-32

R. Stein, RW-23

3 DOE Office of Defense Waste GTN and Byproducts Management

Washington, DC 20545
ATTN:
G. H. Daly, DP-124
J. E. Lyt le, DP-12
T. C. Chee, DP-123

4 DOE Office of Terminal Waste

Disposal and Remedial Action GTN

Washington, DC 20545

ATTN: J. A. Coleman, NE-25

T. W. Mc Intosh, NE-24

W. R. Voigt, NE-20

H. F. Walter, NE-24

A. T, Clark

Division of Fuel Material Safety Nuclear Regulatory Commission washington, DC 20555

G. L. Sjoblom

Environmental Protection Agency

Office of Radjation Programs

401 M Street, S.W.

Washington, DC 20460
No. of

Copies
J. M. McGough

DOE Albuquerque Operations Office

P.0. Box 5400

Albuquerque, NM 87185

P. G. Hagen

Joint Integration 0ffice

Bldg. 3, 2nd Floor

2201 San Pedro N.E.

A]buquerque, NM 87110

E. Maestas

DOE West Valley Operations Office

P.0. Box 191

West Valley, NY 14171

2 DOE Idaho Operations Office

550 Second Street

Idaho Falls, ID 83401

ATTN: S. T. Hinschberger

J. P. Hamric

F. T. Fong

DOE San Francisco Operations

1333 Broadway

Oakland, CA 94612

M. R. Jugan

DOE Oak Ridge Operations Office

P.0. Box E

Oak Ridge, TN 37830

W. J. Brumley

DOE Savannah River Operations Office

P.0. Box A

Aiken, SC 29801 
No. of

Copies

V. Ste 110

Office of the Executive Director for Operations

Majl Station 6209

Nuclear Regulatory Commission

Washington, DC 20555

4 Sandia Laboratories

P.0. Box 5800

Albuquerque, NM 87185

ATTN: Technical Library

B. D. Shipp

Battelle Memorial Institute

Office of Crystalline Repository Development

9800 S. Cass Avenue

Argonne, IL 60439

3 Battelle Memorial Institute

Project Management Division

505 King Avenue

Columbus, $\mathrm{OH} 43201$

ATTN: W. A. Carbeiner

W. S. Madia

Technical Library

L. D. Ramspott

Lawrence Livermore National Laboratory

University of CaTifornia

P.0. Box 808

Livermore, CA 94550

D. T. Oakley, MS 671

Los Alamos National Laboratory

P.0. Box 1663

Los Alamos, NM 87544

4 Oak Ridge National Laboratory

P.0. Box Y

Oak Ridge, iN 37830

ATTN: J. 0. Blomeke

W. D. Burch

R. T. Jubin

L. J. Mezga
No. of

Copies

\author{
M. J Steindler \\ Argonne National Laboratory \\ 9700 S. Cass Avenue \\ Argonne, IL 60439 \\ C. S. Abrams \\ Argonne National Laboratory \\ P.0. Box 2528 \\ Idaho Falls, ID 83401 \\ J. R. Berreth \\ Westinghouse Idaho Nuclear \\ Co. Inc. \\ P.0. Box 4000 \\ Idaho Falls, ID 83401 \\ 7 E. I. du Pont de Nemours \\ and Company, Inc. \\ Savanna River Laboratory \\ Aiken, SC 29801 \\ ATTN: M. D. Boersma \\ J. G. Glasscock \\ C. M. Jantzen \\ J. R. Knight \\ M. J. Plodinec \\ C. T. Randall \\ R. G. Baxter
}

E. A. Jennrich

EG\&G Idaho

P.0. Box 1625

Idaho Falls, ID 83415

R. Williams

EPRI

$3412 \mathrm{Hillview} \mathrm{Avenue}$

P.0. Box 10412

Palo Alto, CA 94304

6 West Valley Nuclear Services Co.

P.0. Box 191

West Valley NY 14171

ATTN: C. C. Chapman

J. E. Krauss

S. J. Marchette

J. M. Pope

L. R. Eisenstatt

S. M. Barnes 
No. of

Copies

J. L. White

Energy Research and Development Authority

Empire State Plaza

Albany, NY 12223

\section{ONSITE}

10 DOE Richland Operations Office

J. H. Anttonen

E. A. Bracken

G. J. Bracken

C. E. Collantes

C. R. Delannoy

J. R. Hunter

J. L. Rhoades

J. J. Sutey

M. W. Shupe

J. D. White

12 Westinghouse Hanford Company

T. E. Dabrowski/W. J. Kyriazis

J. M. Henderson

R. E. Lerch

J. L. NeTson

R. D. Prosser

G. L. Scott

D. A. Turner

J. D. Watrous

D. D. Wodrich

R. D. Wojtasek

B. A. Wolfe

File Copy

65 Pacific Northwest Laboratory

C. R. Allen

W. W. Ballard, Jr.

S. 0. Bates

W. F. Bonner

W. M. Bowen

D. J. Bradley

R. A. Brouns (2)
No. of

Copies

H. C. Burkholder

J. R. Carrell

D. G. Coles

L. J. Ethridge

D. W. Faletti

H. A. Haerer

L. K. Holton

M. R. Kreiter

W. L. Kuhn (3)

W. W. Laity

L. T. Lakey (2)

D. E. Larson

S. F. Liebetrau

J. A. Mahaffey

E. E. McClanahan

J. L. McElroy

G. B. Mellinger

J. E. Mende 1

J. E. Minor

R. N. Nakaoka

A. R. Olsen

A. M. Platt

J. M. Perez, Jr.

R. D. Peters

M. E. Peterson

J. A. Powell

B. A. Pulsipher (10)

M. A. Reimus

P. W. Reimus (2)

J. T. A. Roberts

W. A. Ross

K. J. Schnejder

G. J. Sevigny

S. C. Slate

J. L. Straalsund

M. R. Toland

J. H. Westik, Jr.

Publishing Coordination (2)

Technical Information (5) 
